\title{
REVISÃO SISTEMATICA SOBRE O USO DE DICLORETO DE RÁDIO NA TERAPEUTICA DO CÂNCER DE PRÓSTATA
}

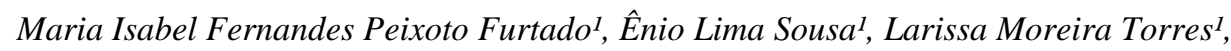 \\ Samya de Araujo Neves ${ }^{2}$
}

\begin{abstract}
Resumo: Atualmente está sendo feito o uso do Dicloreto de Rádio no tratamento do Câncer de Próstata em pacientes que não respondem a redução dos hormônios masculinos (castração) associado a metástases ósseas, que não apresentam metástases sistêmicas e que estão sintomáticos. Este estudo pretende avaliar o potencial terapêutico do Dicloreto de Rádio, assim como os riscos e benefícios do seu uso no tratamento do Câncer de Próstata metastático resistente a castração. Trata-se de uma revisão sistemática da literatura acerca da temática de terapias inovadoras e uso de radiofarmacos no tratamento de cânceres, com enfoque no Dicloreto de Rádio usado na terapêutica do Câncer de Próstata metastático resistente a castração. Os dados foram coletados nas bases de dados Scielo, Pubmed e Lilacs no período de Fevereiro de 2018, com os seguintes descritores em inglês: "radio chloride oncology therapy", "radio dichloride of prostate cancer". Foram encontrados 12 artigos, publicados entre 2014 e 2018, dos quais 4 foram selecionados por maior adequação à proposta pesquisada. A terapia com o radiofarmaco Dicloreto de Rádio mostrou resultados animadores. Sua segurança e eficácia foram avaliadas pelo estudo ALSYMPCA que revelou o aumento da sobrevida global dos pacientes tratados com o Dicloreto de Rádio em comparação com o grupo de pacientes que foram submetidos à terapia com placebo. Homens com Câncer de Próstata metastático resistente a castração apresentam pouca sobrevida, apesar da terapia intensiva. Esse fato levou a avanços recentes na terapia destinada a tratar metástases ósseas resultantes dessa patologia. Nesse contexto, o uso de Dicloreto de Rádio se mostrou eficaz. Estudos internacionais e nacionais em diversos centros oncológicos mostraram redução da chance de morte em $30 \%$ dos pacientes. Essa terapia envolve o uso de radiação direcionada à metástase óssea, diminuindo consideravelmente os sintomas como a dor e os efeitos colaterais por focar com precisão na destruição das células malignas.
\end{abstract}

Palavras-chave: câncer, próstata, dicloreto de rádio, terapia oncologica, Radium-223

\footnotetext{
1 Acadêmico(a) de Medicina na Faculdade Estácio de Juazeiro;

${ }^{2}$ Professor-Doutor na Faculdade Estácio de Juazeiro do Norte;

Autor Correspondente: rolim.bel@gmail.com.

36 Id on Line Rev. Mult. Psic. V.12, N. 40. 2018 - ISSN 1981-1179 EDIÇÃO ESPECIAL: I CURSO DE ONCOLOGIA DO CARIRI / II JORNADA DE PESQUISA QUANTI-QUALITATIVA EM ONCOLOGIA. JUAZEIRO DO NORTE, 05 A 10 DE MARÇO DE 2018. Edição eletrônica em http://idonline.emnuvens.com.br/id
} 